\title{
Commentary
}

\section{Sugar-sweetened beverage tax: the inconvenient truths}

An increasing number of countries and jurisdictions around the world have introduced regulatory measures to curb consumption of sugar-sweetened beverages (SSB). In 2017 alone, Portugal, Brunei, Saudi Arabia, United Arab Emirates, Thailand, the Catalan region of Spain and five US cities introduced a tax on SSB, with planned 2018 SSB tax implementation for the UK, the Republic of Ireland, South Africa, Estonia and the US city of Seattle, Washington ${ }^{(1)}$.

In Australia, a large number of public health, academic and consumer groups now support the introduction of a tax on $\mathrm{SSB}^{(2)}$. However, political support has been limited, with only one party - the Greens - developing a policy platform supporting a tax in Australia ${ }^{(3)}$. The intended benefits of an SSB tax are fourfold: (i) an increase in the retail price of SSB would reduce consumption and produce public health benefits; (ii) generation of substantial revenue, which could be reinvested back into public health; (iii) communication of a powerful message that regular consumption of SSB is not part of a healthy diet; and (iv) incentive for manufacturers to reformulate to lower-sugar products (if tax is tied to the amount of sugar contained in the beverage).

Although political momentum for a tax on SSB is growing internationally, it faces stiff opposition by industry. For example, the American Beverage Association spent more than \$US 2 million in the city of Berkeley, California and more than \$US 9 million in Philadelphia, Pennsylvania opposing an SSB $\operatorname{tax}^{(4)}$. Opposing measures included the saturation of cities with anti-tax advertising to sway public opinion against the proposal and filing multiple lawsuits to repeal the tax (with the appeal from the American Beverage Association reaching the state's Supreme Court in Philadelphia) ${ }^{(5)}$. While this was not enough to defeat the tax at the ballot box in Berkeley and Philadelphia, industry has worked tirelessly to convince both the public and decision makers that a tax on SSB is poor policy. In Australia, the Australian Beverages Council, the peak lobby group for sugary drink companies, has targeted key politicians and political parties to keep a tax off the policy table ${ }^{,(6)}$. Further they acted to form a 'sugar roundtable' made up of groups that could potentially be impacted by a tax, including peak advertising, sugar, cane growers, advertisers and business groups, to actively oppose consideration of a tax by politicians ${ }^{(6)}$.

Two-thirds (63.4\%) of Australian adults and one in four (27.4\%) Australian children aged 5-17 years are classified as overweight or obese ${ }^{(7)}$. Strong scientific evidence, from prospective studies and randomized controlled trials, implicate regular SSB consumption with an increased risk of long-term excess weight gain for both adults and children $^{(8)}$. Consumption of sugary drinks is also a key risk factor for tooth decay in children. In Australia, one in two 12-year-old children presents with dental decay in their adult teeth from free sugar intake ${ }^{(7)}$, of which SSB contribute approximately half this free sugar $^{(9)}$. Daily consumption of SSB increases the risk of developing diabetes by $26 \%$ compared with occasional SSB consumers ${ }^{(10)}$ and has been implicated in a number of other non-communicable diseases ${ }^{(11)}$. Approximately one-third of Australian (aged $\geq 2$ years) reported consuming SSB in the $24 \mathrm{~h}$ prior to the 2011-12 National Health Survey, with children and adolescents the highest consumers ${ }^{(12)}$. Despite these alarming statistics, both major political parties in Australia have rejected the idea of an SSB tax.

As countries around the world debate an SSB tax, proponents must be armed with strong and consistent evidence-based arguments that both justify the policy and counter opposing sentiments. This is critical for advocacy efforts to ultimately influence political decisions. While the public health community has been diligent in justifying an SSB tax, consistent counterarguments are often fragmented and incomplete. Here we present the key opposing arguments against an SSB tax (put forth by the Australian Beverages Council) with corresponding counterpoints (see Table 1). While the arguments and counterpoints have been developed from an Australian perspective, these are likely to be transferable more generally across the world, particularly within other highincome countries.

The economic, social and health benefits of an SSB tax are strong. This now is recognized by many reputable health bodies around the world ${ }^{(13)}$. No longer can the pursuit of profits be prioritized over concern for the health of our children and young people.

\section{Acknowledgements}

Financial support: This commentary received no specific grant from any funding agency in the public, commercial or not-for-profit sectors. Conflict of interest: The authors declare no conflicts of interest. Authorship: Both authors contributed equally to this commentary. Ethics of human subject participation: Not applicable. 
Table 1 Opposing arguments for a tax on sugar-sweetened beverages (SSB) by the Australian Beverages Council and counterpoints

\section{Opposing argument \\ Free sugar consumption is declining and SSB} contribute a small amount to the overall $\operatorname{diet}^{(14)}$

The focus on SSB is unjustified ${ }^{(15)}$

There is limited support for a tax on $\mathrm{SSB}^{(14)}$

Similar taxes in other countries have failed ${ }^{(14)}$

A tax on SSB will be regressive and hit the poor the hardest $^{(14)}$

A tax on SSB will harm business and cost jobs ${ }^{(12)}$

The beverage industry is committed to be part of the solution. Maintaining an energy balance between what is consumed throughout the day and what is burnt off holds the key to maintaining a healthy weight $^{(15)}$

\section{Counterpoint}

Free sugar consumption remains unacceptably high

Australians consume on average 14 teaspoons sugar/d, with half of all Australians (mostly children and teenagers) aged $\geq 2$ years

exceeding the WHO recommended limit for sugar intake (10\% of total energy intake; approximately 12 teaspoons sugar/d) ${ }^{(12)}$

Teenage boys, the highest consumers, consume almost double the WHO recommendation (22 teaspoons sugar/d), with the top $10 \%$ Teenage boys, the highest consumers, con
consuming in excess of 38 teaspoons $/ \mathbf{d}^{(12)}$

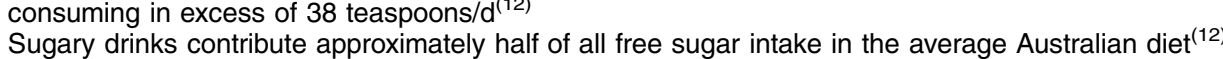

One-third of all Australians (aged $\geq 2$ years) consume sugary drinks regularly (classified as consuming an SSB in the $24 \mathrm{~h}$ prior to the day of the survey) $)^{(7)}$. In 2011-12 this included one in three children aged 2-3 years, a time when taste preferences and eating behaviours are being moulded for the rest of their lives

SSB are the largest source of free sugar in the daily $\operatorname{diet}^{(12)}$

SSB contain little to no nutritional benefit and are not compensated for in the diet by eating less food ${ }^{(16)}$

Drinking SSB leads to increased preference for other sugary foods ${ }^{(17)}$

SSB can be easily defined as a category for taxation

More than twenty jurisdictions around the world have now implemented a tax on $\mathrm{SSB}^{(18)}$

$69 \%$ of Australians support the policy if the revenue was reinvested back into health ${ }^{(19)}$. Successful SSB taxes in the USA have been determined by citizen ballot votes ${ }^{(18)}$

A number of public health and consumer groups support the application of a tax on sugary drinks ${ }^{(13)}$

Evidence from Mexico shows that a $10 \%$ tax on SSB can reduce their purchase by up to $12 \%$ one year post policy implementation ${ }^{(20)}$, with sustained impacts after two years

Claims by industry that SSB sales have rebounded (by $0.2 \%$ ) in Mexico in 2015, two years post SSB tax implementation, are based on data that do not take account of population growth in Mexico, which is increasing at a rate of $1.2 \%$ per year

Any impact that an SSB tax may have on obesity rates is likely to be small and the effect will take several years to measure. Regardless, Any impact that an SSB tax may have on obesity rates is likely to be small and the effect will take several years to measure. Regardless, a tax on SSB should not be viewed as the only element to address obesity and chronic disease. A comprehensive approach including a range of interventions will be essential to make a meaningful impact on the population prevalence of obesity. A poor diet is a leading risk
factor for the global burden of disease, globally, and any improvement to population diets (i.e. via a reduction in SSB consumption) will be a positive step to improve health

While low-income households are likely to pay more in tax, as a proportion of their household incomes, compared with high-income households, this difference is estimated to be modest at less than \$US 5 per year ${ }^{(21)}$

A higher burden of disease and greater responsiveness to an SSB tax among lower-income households ${ }^{(20)}$ will result in progressive health benefits and long-term savings in individual health-care expenditure ${ }^{(22)}$

Reinvestment of revenue into interventions that benefit lower socio-economic strata would further enhance the positive impacts for disadvantaged individuals and families

Evidence demonstrates a shift in demand to non-sugary drinks following the implementation of an SSB tax ${ }^{(20)}$; this increased production of Evidence demonstrates a shift in demand to non-sugary drinks following the implementation of an SSB tax ${ }^{(20)}$; this in
non-sugary drinks is likely to minimize job losses in the beverage industry. Modelling studies support this ${ }^{(23)}$

Analysis of changes to employment following the SSB tax in Mexico demonstrated no change in employment in the non-alcoholic beverage manufacturing industry and a negligible increase in employment in commercial establishments that sell foods and beverages ${ }^{(24)}$

The reinvestment of revenue will create jobs in other sectors

The beverage industry has an unavoidable conflict of interest as a publicly listed company. These companies have a legal obligation to act in the interests of their shareholders and maximize sales and profits to the full extent permitted by law

The industry has funded research to obfuscate the evidence, run campaigns with a focus on physical activity and supported recommendations that are relatively weak and ineffective as alternatives to stronger action by government ${ }^{(25,26)}$ 
Kathryn Backholer

The Global Obesity Centre (GLOBE), School of Health and Social Development, Deakin University, Locked Bag 20000, Geelong, VIC 3220, Australia, Email: Kathryn.backholer@deakin.edu.au

Department of Epidemiology and Preventive Medicine, School of Public Health, Monash University, Melbourne, Australia Jane Martin
Obesity Policy Coalition/Cancer Council Victoria,
Melbourne, Australia

\section{References}

1. Backholer K, Blake M \& Vandevijvere S (2017) Sugarsweetened beverage taxation: an update on the year that was 2017. Public Health Nutr 20, 3219-3224.

2. The Obesity Policy Coalition (2017) Tipping the Scales: Australian Obesity Prevention Consensus, Australia. http:// www.opc.org.au/tipping-the-scales.aspx (accessed October 2017).

3. The Australian Greens (2016) Taxing Sugary Drinks. Fighting childhood obesity - healthy choices for a long and healthy life. https://greens.org.au/sugar-tax (accessed October 2017).

4. Centre for Science in the Public Interest (2016) Big Soda vs. Public Health (2016 Edition). https://cspinet.org/resource/ big-soda-vs-public-health-1 (accessed October 2017).

5. Kopp J (2017) Big Soda appeals Philadelphia tax to state Supreme Court. Philly Voice, 17 July. http://www.phillyvoice. com/american-beverage-association-appeals-philadelphiasoda-tax-ruling/ (accessed October 2017).

6. Australian Beverages Council (2017) Australian Beverages 2016 Annual Report. Waterloo, NSW: Australian Beverages Council.

7. Australian Institute of Health and Welfare (2016) Australia's Health 2016. Catalogue no. AUS 199. Canberra: AIHW.

8. Te Morenga L, Mallard S \& Mann J (2012) Dietary sugars and body weight: systematic review and meta-analyses of randomised controlled trials and cohort studies. BMJ $\mathbf{3 4 6}$, e7492.

9. Anderson A, Dewar J, Marshall D et al. (2007) The development of a healthy eating indicator shopping basket tool (HEISB) for use in food access studies - identification of key food items. Public Health Nutr 10, 1440-1447.

10. Malik VS, Popkin BM, Bray GA et al. (2010) Sugar-sweetened beverages and risk of metabolic syndrome and type 2 diabetes: a meta-analysis. Diabetes Care 33, 2477-2483.
11. Fung TT, Malik V, Rexrode KM et al. (2009) Sweetened beverage consumption and risk of coronary heart disease in women. Am J Clin Nutr 89, 1037-1042.

12. Australian Bureau of Statistics (2016) Australian Health Survey: Consumption of Added Sugars 2011-12. Report no. 4363.0.55.011. Canberra: ABS.

13. Veerman JL, Sacks G, Antonopoulos N et al. (2016) The impact of a tax on sugar-sweetened beverages on health and health care costs: a modelling study. PLoS One 11, $\mathrm{e} 0151460$.

14. Australian Beverages Council (2017) Why a soft drinks tax is not the answer. http://www.australianbeverages.org/forconsumers/soft-drink-tax-answer/ (accessed September 2017).

15. Australian Beverages Council (2017) Energy balance. http:// www.australianbeverages.org/for-consumers/soft-drinks-ineveryday-life/ (accessed October 2017).

16. Pan A \& Hu FB (2011) Effects of carbohydrates on satiety: differences between liquid and solid food. Curr Opin Clin Nutr Metab Care 14, 385-390.

17. Ventura AK \& Mennella JA (2011) Innate and learned preferences for sweet taste during childhood. Curr Opin Clin Nutr Metab Care 14, 379-384.

18. Backholer K, Blake M \& Vandevijvere S (2016) Have we reached a tipping point for sugar-sweetened beverage taxes? Public Health Nutr 19, 3057-3061.

19. Morley B, Martin J, Niven P et al. (2012) Public opinion on food-related obesity prevention policy initiatives. Health Promot J Aust 23, 86-91.

20. Colchero MA, Popkin BM, Rivera JA et al. (2016) Beverage purchases from stores in Mexico under the excise tax on sugar sweetened beverages: observational study. BMJ 352, h6704.

21. Backholer K, Sarink D, Beauchamp A et al. (2016) The impact of a tax on sugar-sweetened beverages according to socio-economic position: a systematic review of the evidence. Public Health Nutr 19, 3070-3084.

22. Lal A, Mantilla-Herrera AM, Veerman L et al. (2017) Modelled health benefits of a sugar-sweetened beverage tax across different socioeconomic groups in Australia: a costeffectiveness and equity analysis. PLOS Med 14, e1002326.

23. Powell LM, Wada R, Persky JJ et al. (2014) Employment impact of sugar-sweetened beverage taxes. Am J Public Health 104, 672-677.

24. Guerrero-López CM, Molina M \& Colchero MA (2017) Employment changes associated with the introduction of taxes on sugar-sweetened beverages and nonessential energy-dense food in Mexico. Prev Med, (Epublication ahead of print version).

25. Nestle M (2016) Corporate funding of food and nutrition research: science or marketing? JAMA Intern Med 176, $13-14$.

26. Pfister K (2016) Coke funds research against soda taxes. https://medium.com/cokeleak/coke-funded-research-againstsoda-taxes-4289d897bde3 (accessed October 2017). 